\title{
A clinical educator's experience using a virtual patient to teach communication and interpersonal skills
}

Frank Bánszki, Janet Beilby, Michelle Quail, Peter J. Allen

Curtin University, Australia

Shelley B. Brundage

George Washington University, Washington, DC

Josh Spitalnick

Citrine Technologies, Atlanta, GA

\begin{abstract}
The purpose of this study was to explore one novice clinical educator's experiences with training essential communication and interpersonal skills using a virtual patient. Over 3 weeks, the clinical educator (CE) delivered a series of half-day clinical placements to students using an educator-controlled virtual patient, depicting an older adult male with mild dementia. Students completed one 15-minute session interacting with the virtual patient in the virtual learning environment (VLE), followed by a group debrief/discussion session. Prior to, during and after delivering the clinical placements, the CE engaged in semi-structured interviews, where she was prompted to reflect on her pedagogic approach and practice. Thematic analysis revealed six themes underpinning the CE's unique narrative: pedagogical control, validation of pedagogical practice, safety in the virtual learning environment, learning pedagogical practices, self-reflection, and adult education. The CE described how being immersed in the VLE allowed her to confidently deliver training. The findings have implications for the future training of CEs who will provide clinical education using VLEs in clinic settings.
\end{abstract}

\section{Introduction}

The consistent delivery of high quality allied health services in Australia is inextricably linked to universities designing educational programs that provide students with clinical training opportunities in the workforce (Health Workforce Australia, 2011). In speech-language pathology this has been accomplished through the use of professionally accepted clinical placement and supervision models (Sheepway, Lincoln, \& Togher, 2011), herein collectively called clinical education models. Individual supervised training, conducted within block clinical placements in the workforce is the traditional clinical education model (McAllister \& Lincoln, 2004), and is necessary for the development of clinical skills required for graduate entry into the profession. However, increasing student enrolments (Lincoln, 2012), combined with limited workforce placement availability, has created significant pressure on the provision of traditional clinical placements (Theodoros, Davidson, Hill, \& MacBean, 2010).

Traditional clinical education is dependent on the capacity of speech-language pathologists to provide direct, supervised, clinical experiences in the field. In recent years, this capacity has become increasingly constrained due to large caseload demands, increased documentation requirements for recording accountability, high levels of part-time employment, and inexperience in providing clinical education (Rodger et al., 2008). Such workplace pressures may deter and prevent speech-language pathologists from undertaking CE roles. Alternative models have much to offer CEs in contemporary practice. For example, the collaborative model assigns multiple students to each educator, providing opportunities for peer-assisted learning and aiding educators balance their professional and educative duties (Briffa \& Porter, 2013). Nonetheless, "much of the resistance or inability to adopt new approaches to clinical education lies with inadequate preparation and support of CEs” (McAllister, 2005, p. 145). More flexible clinical education methods across workforce settings are necessary in contemporary clinical education for engaging speech-language pathologists to participate in the clinical education of students.

Student clinical training delivered exclusively through traditional methods has been viewed as a "cycle of crisis" that has necessitated a national response in order to sustain the quality of graduates entering the 
health professions (Rose, 2005, p. 158). As such, contemporary clinical education has commenced pedagogical reform at a national level, through Health Workforce Australia's (2014) Simulated Learning Environments program in reaction to the constraints on clinical education opportunities within the Australian workforce. This national program has investigated the validity and feasibility of incorporating simulation-based clinical education models in speech-language pathology curricula, with the objective of delivering more efficient and effective clinical education and training (Theodoros et al., 2010). Exploration of the validity of alternative clinical education models for supplementing traditional and contemporary clinical placement models has been made possible through the professional accreditation process utlising competency-based occupational standards, which allow for flexibility in curricular designs (Ferguson, 2005). This process has been integral to the proliferation of alternative clinical education models in speech-language pathology programs.

\section{Simulated learning environments}

Educators have previously used simulated learning environments (SLEs) to replicate realistic scenarios for the purpose of training clinical skills within a safe environment (Theodoros et al., 2010). SLEs include the use of standardised patients (i.e., trained actors), mannequins, and virtual patients (Theodoros et al., 2010). Compared to traditional clinical placements, SLEs have the benefit of being standardised, permitting educators to deliver controlled, repeatable practice of clinical scenarios that may otherwise be considered uncommon or high-risk.

To date, SLEs have predominately been used to teach essential clinical skills to nursing and medical students (Hill, Davidson, \& Theodoros, 2010). Nevertheless, there is emerging literature supporting the application of SLEs in speech-language pathology education, where they have been used to train generic clinical competencies (MacBean, Theodoros, Davidson, \& Hill, 2013). For example, standardised patients have been used to teach communication and interpersonal skills (Zraick, Allen, \& Johnson, 2003), interviewing skills, client education, responses to confrontation, and administration of therapy techniques (Syder, 1996). SLEs have also been used to train advanced specialised clinical skills, such as the management of tracheostomised patients (Ward et al., 2014). There is, however, limited literature in speech-language pathology education on the applications of virtual-based SLEs for clinical training.

\section{Virtual learning environments}

Virtual learning environments (VLEs) have been defined in the literature as computer-generated virtual environments designed to deliver educational experiences (Mikropoulos \& Natsis, 2011; Mimirinis \& Bhattacharya, 2007). VLEs are educator driven, allowing for a degree of control over the virtual experience to create training situations that mimic real world environments for students. Examples of these VLEs include the use of virtual worlds, virtual caves, and virtual patients (Theodoros et al., 2010). Such VLEs can provide the learner with experiences of clinical immersion, which is the submergence of the learner into the virtual environment (Sutcliffe, Gault, \& Shin, 2005).

Findings regarding the use of VLEs in clinical education for training generic clinical skills (e.g., communication) have predominately been reported in medicine (Bearman, 2003; Deladisma et al., 2007; Lok et al., 2006) and nursing (Foronda, Gattamorta, Snowden, \& Bauman, 2014). For example, Bearman (2003) obtained valuable qualitative insights regarding the use of a VLE from the perspective of medical students. The author conducted a phenomenological investigation of 12 medical students' experiences of training with a virtual patient to develop communication skills. He reported 23 themes including emotional responses of frustration, preoccupation with controlling the medical consultation, and assumptions of the general practitioner role. These students were challenged regarding their experiences of the development of a doctor-patient relationship through the use of virtual patients.

More recently, and within the context of speech-language pathology education, Quail, Brundage, Spitalnick, Allen, and Beilby (2016) randomised 62 third year speech-language pathology students to one of three placement types, with the objective of comparing their relative efficacy vis-à-vis the development of essential communication abilities, knowledge and confidence. In the first placement, students conversationally engaged with an elderly nursing home resident for up to 30 minutes. In the second and third placements, that conversation was with a trained elderly patient actor in an SLE, or with an elderly virtual patient in a VLE. The VLE used by Quail et al. (2016) was the same as that described in the 
current study. Following the interaction, students debriefed with their CE in small groups. Quail and colleagues (2016) found that the students' self-reported communication skills, knowledge and confidence were significantly higher post-placement than they were seven days prior (median $d=.58$ ). They further observed that the degree of change from pre- to post-placement did not vary as a function of placement type (median $\eta^{2}<.01$ ). Finally, although students in the VLE placement reported their experience as more challenging than students in the other two placement groups, all three groups appeared to derive equivalent benefits from their experience. In combination, these findings led Quail and colleagues (2016) to conclude that there is considerable value in integrating VLE placements (alongside traditional workplace based placements) into the speech-language pathology curricula, at least with regards to the training of essential communication skills. However, they also noted the need for further research around the best-practice deployment of these emerging technologies.

\section{The current study}

One area of investigation that has been given relatively scant attention is the response of the CE to the deployment and use of VLE technologies. Prior research suggests that educator acceptance of any new technology is critical for its successful integration into the curriculum (Cheung, Chan, Brown, \& Wan, 2016; Davis, 1993; Yuen \& Ma, 2008). Self-efficacy in the use of technology, ease of use, and perceived usefulness of the technology all contribute to educators' use and acceptance of technology (Davis, 1993; Mamet, Yusoff, Abdullah, \& Razak, 2015; Teo, 2010; Yuen \& Ma 2008). Therefore, the purpose of this qualitative study was to explore the experiences and pedagogic practices of a $\mathrm{CE}$ when teaching communication and interpersonal skills within a VLE clinical education model. Third year undergraduate speech-language pathology students new to clinical practice were the training cohort. The CE used a virtual patient to simulate the clinical placement of an aged care facility. The in-depth experiences of the CE in providing a series of half-day (4-hour) VLE clinical placements to the students over the course of 3 weeks were investigated prior to, during, and upon reflection. In addition to providing a VLE clinical placement with a virtual patient, the CE also trained students in two different placements over the 3-week period: an SLE clinical education model with a standardised patient (i.e., trained actor), and a traditional workforce clinical placement (i.e., residents within an aged care nursing home). The current study aimed to answer the following research question:

What qualitative reflections and experiences are reported by a CE in their use of a VLE prior to, during, and after a foundation clinical education placement?

\section{Method}

\section{Participant}

The participant for this study was a speech-language pathologist employed as a CE to deliver the clinical education placement to third year undergraduate speech-language pathology students at a large metropolitan Australian university. The university's human ethics committee approved the research study. The CE had no prior experience in a clinical education capacity, and received approximately 5 hours formal training regarding communication and interpersonal skills education using a virtual patient prior to meeting her students. Training involved pedagogical instruction and software operational training for control of the VLE user interface (UI) on a laptop computer. We chose a CE who had limited prior teaching experience because "teachers' technology beliefs are influenced by their teaching philosophy" (Teo, 2010, p. 253) and we wanted an unbiased view of the technology and its use.

\section{The virtual patient}

The VLE software is operated on a standard laptop computer and is HDMI-connected to a secondary large screen display for viewing the virtual patient. The high definition television (HDTV) display was life-size. The virtual patient's verbal and non-verbal responses were operated by the CE behind a one-way mirror in an observation room via a laptop. The student entered the training room and then sat behind a desk in front of the virtual patient. The virtual patient, referred to as Jim, was a three-dimensional (3D) computer simulation representation of an older adult (Figure 1). The visual features and voice responses of the virtual patient were recorded and modelled on a real-life nursing home resident. The virtual patient 
was seated in a wheelchair in a clinic room representative of an aged care facility (Figure 2). The clinical scenario for Jim was that he represented a nursing home resident with mild dementia.

The simulation training platform was built with the Unity game engine, an advanced state-of-the art virtual reality development software platform that supports full 3D graphic rendering, physics, and a wide variety of interaction device options. The Unity game engine, high fidelity visuals, and customised animations have been used to enhance the realism and credibility of the simulation content while offering a training experience that is uniquely designed to differentiate it from commercial videogames, static websites, or cartoon like characters. The program includes two simultaneous, run-time applications. The controller application is a run-time controller user interface (UI) and is operated by a human user. It includes a library of verbal and non-verbal options activated by a click of the mouse. A second application is designed and customised for the intended user to interact with in real time and it includes a single virtual patient, with customised demographic characteristics (e.g., gender, attire, ethnicity, body shape, facial features) defined by the clinical team from the university, as well as a location/context (e.g., clinic office) with typical location specific content (e.g., tables, chairs, lamps, ambient sounds, wall furnishings). All language, gestures, motions, and verbal and non-verbal content in the virtual human is controlled by the controller UI.

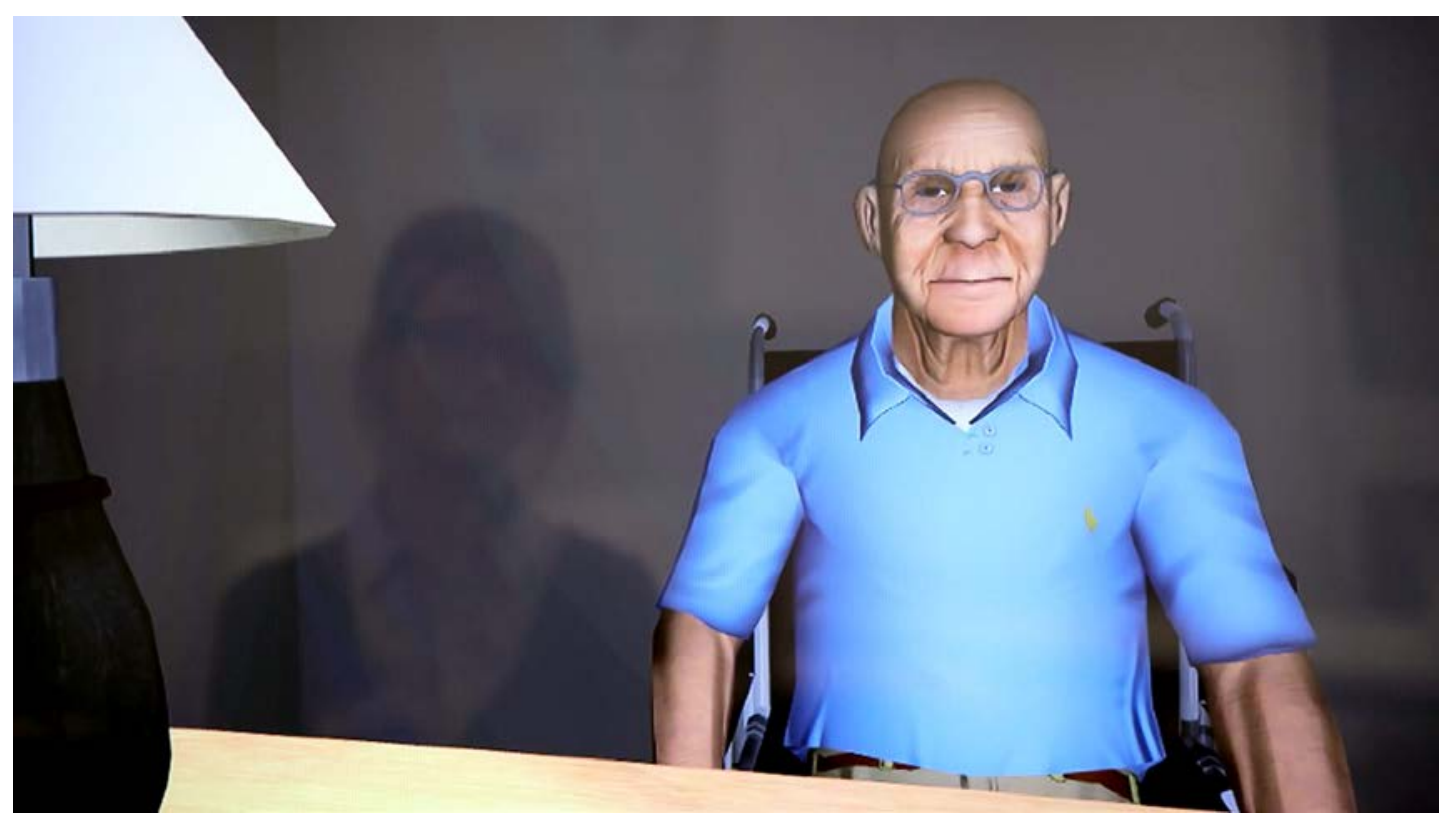

Figure 1. Jim, the virtual patient, as seen from the perspective of a student trainee.

Nineteen 3rd year speech-language pathology students using the VLE for their clinical placement attended a half-day clinical placement within a 3-week block as part of their curriculum requirement. These are the same students who participated in the VLE condition of Quail et al. (2016). On commencement of the placement, each student entered the VLE clinical training room with the virtual patient on the screen, while the CE supervised the individual session from behind a one-way mirror. Each student received up to 15 minutes of one-to-one interaction time with the virtual patient. The student was required to develop rapport within that time using professional communication and interpersonal skills. The student sat on one side of a table approximately 2 metres from the television screen for the interaction with the life-size virtual patient. 


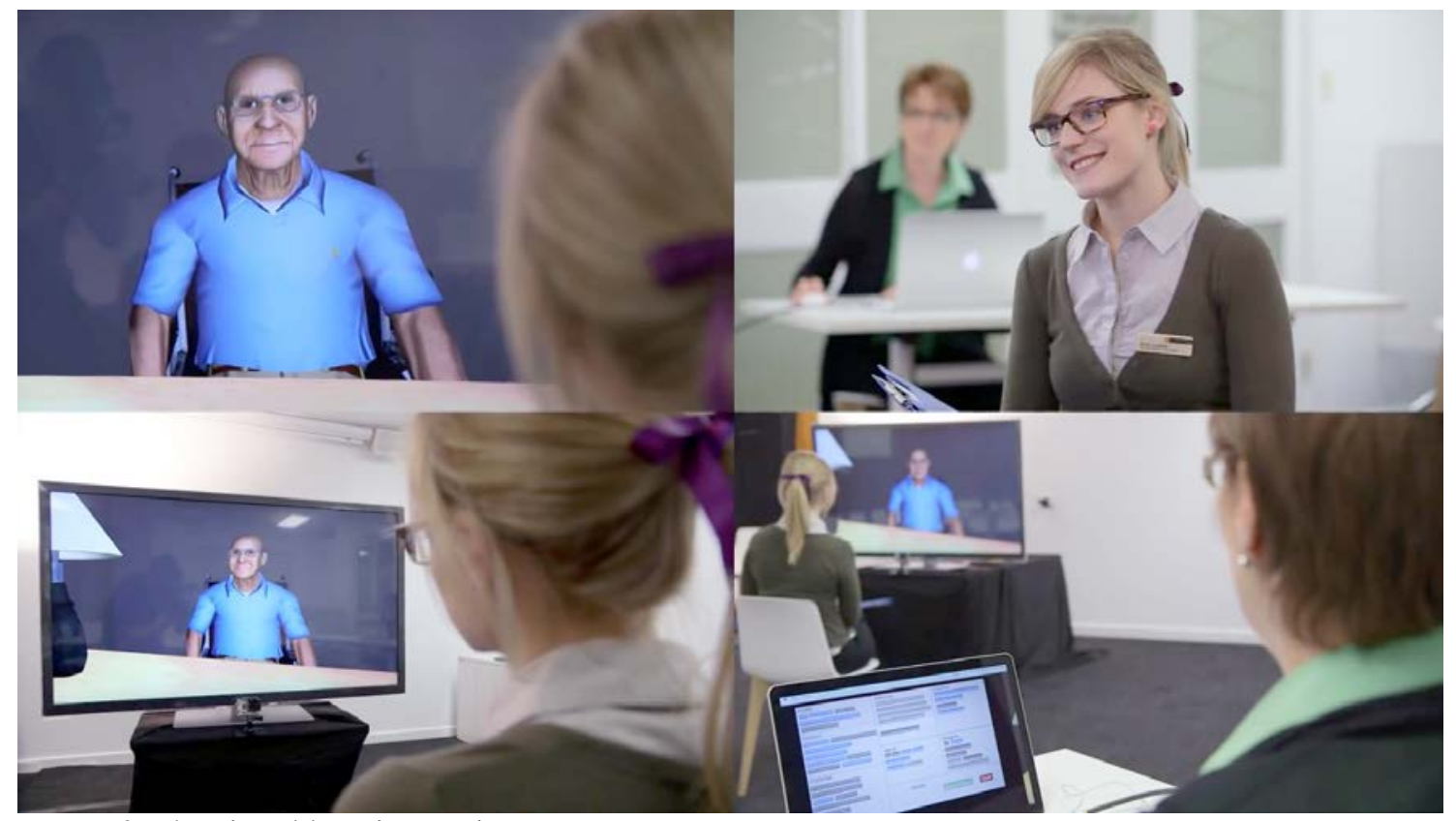

Figure 2. The virtual learning environment.

Note: For illustrative purposes, the CE is positioned behind the student, although in the same room. During the actual placement, she was in a separate observation room, behind a one-way mirror.

The CE's role in providing the VLE clinical placement was to operate the virtual patient using a laptop to initiate pre-programmed verbal and non-verbal responses. As each student communicated with the virtual patient, the CE selected responses to initiate new communication topics or to respond to the student's communication. A total of 45 pre-programmed responses were categorised as challenges, agreements, disagreements, concerns, affective, functional, or client profile responses. These categories, and the 45 options within them, were determined by the clinical and technology research teams to address the most basic but necessary communication choices, while ensuring there were a manageable number of responses to allow the CE to effectively and efficiently operate a realistic virtual patient. The CE's role was also to provide student support and facilitate student self-reflection. Students could leave the clinical training room for support at any time throughout the placement. At the end of each clinical placement day, the CE held a group discussion with all the attending students in order for them to debrief and discuss the clinical placement.

\section{Data collection}

The qualitative interview protocol used with the CE was based on the guidelines delineated by Moustakas (1994), and the interviews were conducted by the first author. A relaxed atmosphere was first established through informal discussions, and open disclosure of the CE's experiences was encouraged via openended questioning (e.g., What thoughts stood out for you while working within a VLE clinical education model?). Supplementary probe questions were used in instances where the CE required prompting for greater description of her experience (Moustakas, 1994). A total of three 20 minute, semi-structured interviews were conducted with the CE, 1 week prior to, during, and 1 week following the 3 week block of clinical placements. The interviews were recorded on a digital audio recording device, allowing for the verbatim transcription of interviews for later analysis.

\section{Data analysis}

This study used a thematic analysis as an inductive method of analysing the qualitative data within a constructivist epistemology (Braun \& Clarke, 2006). The analytical principles underpinning the phenomenological approach for data analysis were also integrated into this process (Moustakas, 1994). The instances of semantic themes and sub-themes were captured through the interpretations of descriptive codes, by taking into account both the relevance of codes to the research question and pattern of occurrence within and across the data sets (Braun \& Clarke, 2006). Although data analysis was led by the 
first author, $10 \%$ of the data were cross-coded with another member of the research team. Inter-coder agreement was initially 95\%, which increased to $100 \%$ following discussion of one ambiguous descriptive code (Lincoln \& Guba, 1985).

\section{Results}

Analysis of the interview transcripts revealed six themes regarding the CE's experience of delivering clinical skills training to undergraduate third year speech-language pathology students within a VLE clinical education model. Emergent themes were delineated across interviews conducted 1 week prior to, during, and 1 week following the clinical placements, summarising six themes that unfolded longitudinally within the CE's description of her pedagogical experience. The themes described preconceptions and pedagogical reactions to the use of the virtual patient for teaching students. The results revealed positive adaptions in the CE's pedagogical approach and increases in her pedagogical skills. The six major themes were: (1) pedagogical control; (2) validation of pedagogical practice; (3) safety in the virtual learning environment; (4) learning pedagogical practices; (5) self-reflection; and (6) adult education.

\section{Prospective views}

One week prior to delivering the clinical placement, the CE discussed her views in anticipation of undertaking clinical skills training in a VLE clinical education model. The theme of pedagogical control emerged in the CE's prospective views of the placement:

I'm going to be the person controlling the [virtual patient], the learning experience, so I'll have the opportunity to probably provide the students with unique opportunities.

There was indication of a desire to take control of the clinical placement, in order to provide safe and equitable learning experiences for the students. Extending from this view, the theme of safety in the virtual learning environment also emerged:

I think there would be less problems with the VLE, but probably more in terms of the nursing home resident or the hospital simulation. I think there's more chance that there will be a situation that may arise that a student would find confronting in terms of a response to a question or if the nursing home resident gets teary about, you know ... So if it's in a room and there's a photo and you ask "Who's that?" “That's my husband, he passed away last week". So that might be concerning for a student and that would require a bit more counselling and support, as opposed to the VLE where, you know, he's Jim.

Further anticipation of challenges working with a VLE model were described, as well as expectations around the need to effectively draw on professional pedagogical skills for teaching communication and interpersonal skills. The CE postulated that students may hold negative preconceptions about the VLE model as a clinical placement. In these prospective views, the CE highlighted a need to validate the pedagogical practice of using a virtual patient for teaching clinical skills:

[Students] may not like this condition at all. And then that'll be a case of me having to justify why this is a valuable learning tool.

Subsequently, the theme validation of pedagogical practice emerged. The CE also described wanting to provide clinical support to encourage self-directed learning for students, which resulted in the theme adult education emerging prospectively:

My key role is to provide the tools for the students, to get the students to think deeper about their practice and give them something to take into their placements. I think it takes time for students to develop good reflection skills, to understand what a reflection is, and to teach those skills. 


\section{Experiences during the clinical placement}

At the conclusion of the first week of the 3-week clinical placement block, the CE had delivered 7 hours of clinical education. Her experiences were discussed with the first author in a second interview. The themes of pedagogical control and safety in the virtual learning environment developed from those discussions. The CE reported experiencing a loss of control of the clinical skills training sessions, expressing a desire to regain control of students' conversations with the virtual patient:

I will ... try and not only challenge them, but to redirect them to a different line of questioning that may be more supportive.

In addition, in this interview, the CE described not being able to control the virtual patient/student conversations, particularly for students who required more support. Some students became overwhelmed with the confrontations of communication breakdowns while talking to Jim, the virtual patient:

She had difficulty in redirecting her questions in a way that Jim could give a viable response. With a lot of questions, he had to go with "I can’t remember" or "I don’t know", and a few of the "I want to drive again" interspersed in there. Leading up [to her crying] it was, her line of questioning was, I don’t know. It was nothing different; he hadn’t used any of his challenges with her. And it was quite early in the interaction when she came out.

The CE expressed surprise with such responses and in turn took on a greater supportive clinical role as needed:

I did let them know that if they became overwhelmed, just to excuse themselves and come out and I would meet them in the corridor just to debrief.

On the one occasion a student could not continue the exchange, the CE observed:

She felt silly that she was crying. She said, “I don’t know why I was crying”. I said, "It’s not easy, you know, other people have tried this and they have struggled. You're doing really well. You have a nice pace of questioning.”

The theme validation of pedagogical practice continued with the CE's description of the discussions held generally with students about their clinical placement. The CE described how students had negative attitudes and anxiety towards the VLE clinical education model, which was perceived to impact on their self-reflections of their clinical performance. The CE reiterated to the students that clinical training of their communication and interpersonal skills with a virtual patient was beneficial to their development of clinical competency:

Just because it's on the computer, it doesn't mean that he is going to be any different from other conditions or a client with dementia.

The CE described feelings of frustration when unable to change the perceived negativity of students towards the VLE experience:

I wasn't sure how the VLE would go. I thought that they would come out not as positive with the experience. I didn’t expect [students] to be challenged. I certainly didn’t expect any to take that time out. I thought they would not feel so overwhelmed by that experience.

The themes of self-reflection and learning pedagogical practices were evident during evaluations of the CE's experience in conducting the clinical placement. The CE talked about engaging in self-reflection of her own clinical knowledge and prior experiences of communication with older adults with dementia:

And then I gave them examples from my own placements. I said sometimes you don't get that. You know with people with dementia or brain injury, they can't give you that back and forth conversation. 
The CE illustrated by example, the associations between the limited verbal expressions of the virtual patient, and her real-life encounters with clinical patients with dementia. The CE described a positive increase in confidence, and described growth in her pedagogical skills as a CE after 1 week of clinical education in the placement:

I've really loved the clinical education side. What I've learned personally is that I was able to support the students and give them a lot more information than I thought. And that I was able to feedback constructively, and give them a good range of strategies and tools to take with them after this experience.

The theme adult education continued to develop when the CE described students as apprehensive, yet professional when communicating with the virtual patient:

You don't need to rely on him doing all the talking. And I think that's what they relied on. You know, when you are in a nursing home, you get that.

Further observations pertained to how some students were self-directed in their learning of this experience:

The VLE, they found I guess more difficulty interacting with him and therefore, were able to reflect on their experience a lot better.

In contrast, the CE described a student who did not make the most of the clinical placement:

There was one particular student I don't think she took it seriously enough and just saying, "It's a computer." Or "I feel like I could have done better if I was with a real person". And that was frustrating, because I guess what I can see from my experience that she hasn't learned yet.

\section{Retrospective views}

The retrospective views of the CE were obtained in an interview held one week following the conclusion of the clinical placements. validation of pedagogical practice continued as a consistent theme. The CE described needing to justify the VLE to students who believed they would have benefitted more from interacting with a nursing home resident than in the VLE clinical education model. As a result, the CE used examples of when students were challenged while communicating to the virtual patient as the basis for validating the experience:

There were a few [students] on a whole; they did say they would have preferred the nursing home [clinical placement].

And I had to put to them that ... you were all challenged in here, because there were questions you couldn't answer. And that is when some of them put their backs up and said, "Well that's outside my scope of practice".

The CE described feelings of sadness and frustration towards teaching students who were not practising their communication and interpersonal skills with the virtual patient.

At times I felt a little bit sad for Jim, in the fact that, I would have liked to see the students give him a little bit more. I feel they may have, if it was a real person in the same situation. [Researcher: You felt sad?] Yeah, sadness, and frustration with some of them, that they didn’t pursue it. You know, it's [a virtual patient]. So it's not going to walk out of the room.

Pedagogical control and safety in the virtual learning environment emerged as ongoing and intertwined themes of the CE's retrospective experiences. The CE described having limited control of the virtual patient/student dyad for developing conversation. The CE overcame perceived limitations by 
standardising the challenging interactions, and focusing more on the post-session discussions for enhancing student learning.

One student, I did use the "Goodbye now" before she had finished, and that was because there were big gaps in silence. And I was like, this is ridiculous. And she found that difficult.

I started off easy, and then I just challenged them all. The first group, I was reluctant to use the fist on the table [response], and "I don't want to be here" [response]. But by the end of it, pretty much all of the students had that fist, "I don’t want to be here", or crying [response from the virtual patient]. [Researcher: Why?] Because they struggled to expand on their conversations.

The CE exerted pedagogical control through selecting the most confronting responses of the virtual patient. These responses were used to challenge students' skills in maintaining the interactive flow of conversation. The CE viewed this as an opportunity to provide feedback and instructional teaching regarding students' communication and interpersonal abilities within the post-session group debrief and discussions:

So where they struggled, or in their responses to Jim, I was actually able to draw from my own personal experiences and my knowledge of the aged care sector.

The themes of learning pedagogical practices and self-reflection continued to emerge in the CE's retrospective reflections. The CE reported how her confidence increased across the 3 weeks of clinical placements, and how this was accompanied by feelings of accomplishment and the development of her pedagogical skills:

I felt that I helped the students achieve what the aims of the experiences were, to give them experience communicating with an older adult.

A refinement of pedagogical practice occurred over time. The CE achieved this by reflecting on her own clinical experiences of communicating with older adults with dementia and then role-playing Jim, the nursing home resident. She described getting into the headspace of a nursing home resident when operating the virtual patient:

I needed to visualise Jim's wife coming in to see him. I needed to be in that headspace. Otherwise ... my mind wandered ... was less effective in terms of the [virtual patient's] responses.

When I was operating Jim, then I became Jim.

The theme of adult education developed at the end of the experience. The CE discussed her opinion that third year speech-language pathology students had difficulty simply having a conversation without any clinical direction through a goal-orientated practicum scenario. She reported that students wanted to develop more practical rather than interaction skills from their experience. The CE reported that, while understanding this viewpoint, it was nevertheless frustrating that some students did not utilise the clinical placement as an opportunity to consolidate their communication and interpersonal skills.

It had the greatest learning potential, because we learn from our mistakes. And so in the VLE, students made more mistakes. Some students recognised that. Some students didn't recognise that. They just thought it was Jim's fault that they could not talk for more than 5 minutes.

The potential that this experience had for students to develop, refine, or extend their clinical communication and interpersonal skills was highlighted throughout the interviews. 


\section{Discussion}

The aim of this study was to gain insights about the experiences of the CE when training communication and interpersonal skills within a VLE clinical education model. The CE's description of her experiences revealed six major themes, which evolved over the course of delivering 3 weeks of intensive clinical placements. These themes mirror previous literature suggesting that educators are more likely to use technology such as VLEs if they: (a) perceive it to be useful to student learning, (b) regard the technology as easy to use, and (c) have positive attitudes toward their own ability to use the technology (Davis, 1993; Li, 2015; Mamet et al., 2015; Teo, 2010).

The themes of pedagogical control, validation of pedagogical practice, and safety in the virtual learning environment were connected within the CE's description of her experience. The majority of students benefited positively from the learning afforded them in the VLE placement. However, by contrast, several students were observed by the CE to experience unforeseen anxiety and frustration within the VLE. Consequently, the $\mathrm{CE}$ observed a diverse range of learning experiences from a large number being positively engaged to a select few being disengaged. This both surprised and frustrated the CE.

The CE reacted to students' negative responses with the learning process in the VLE by challenging all students with confronting patient behaviours, such as making the virtual patient bang his fist on the table and saying, "I don't want to be here". This was a reaction from the virtual patient that the CE was initially reluctant to use with students. However, this reaction resulted in a more challenging and authentic experience for students. Such challenging interactions with the virtual patient provided a foundation for the CE to provide instructional teaching with students in a group debrief and discussion session held at the end of the clinical day. As a result, the CE felt more confident in highlighting specific training for students in the consolidation of their communication and interpersonal skills. These themes suggest that the CE perceived the VLE to be useful for student learning, a significant indication of future VLE use in pedagogical settings (Mamet et al., 2015; Teo, 2010).

The themes labelled learning pedagogical practices, self-reflection, and adult education provided insights to the CE's development of pedagogical skills over the course of the placement. The CE described a responsibility for supporting students in attaining their learning outcomes, but had preconceived prejudice in the value of VLE would provide. Although all students did not uniformly like the modality of training, the VLE did positively challenge students' assumptions about their own clinical abilities for interacting with older adults with cognitive-communication impairments. Students were observed to have difficulty being self-directed in their learning, as they were focused on the perceived priority of acquiring more practical skills rather than interaction clinical skills as part of their third year curriculum. The CE dealt with this by reinforcing their self-directed learning behaviours, which is an intrinsic part of the education of adult learners (Knowles, Holton, \& Swanson, 2011).

The CE also noted how the VLE changed her pedagogical role (Hutchings \& Quinney, 2015). The CE described becoming an active participant in the experience by role-playing as a nursing home resident through the virtual patient. In this model, immersion was considered only to be significant to student learning. However, the CE's narrative suggests that she might have also benefitted from learning through clinical immersion in the VLE by taking the perspective of the virtual patient while receiving training of her pedagogical skills. In this study, the CE received training that focused more on the technical/operational components of the VLE in preparation for delivering the clinical placement. Only when the CE experienced clinical immersion into the VLE through reflecting on her clinical practices with clients with dementia, and then role-playing through the perspective of the virtual patient, did she perceive an increase in her confidence for using the VLE to train students. This followed a perceived improvement in the efficiency of her pedagogical skills by conducting up to eight 15-minute clinical training sessions across a single clinical placement day.

Through the intensive 3-week schedule of delivering clinical education, the novice CE developed proficiency and confidence to become an experienced educator, evidenced by her descriptions of pedagogical adaptations, and ability to engage resistant and/or anxious students in the learning process. In turn, the majority of students benefitted from the challenges of their experience by working hard to develop the conversation with the virtual patient for building rapport. In the current workforce climate, integrating VLEs into contemporary speech-language pathology education programs for pre-clinical 
training of essential professional skills may be useful as a means for supplementing traditional and contemporary clinical education structures for enhancing and supporting workforce clinical education experiences.

\section{Limitations and future directions}

This study investigated the pedagogical experience of a CE with no prior experiences in this role. Although a potential limitation, obtaining insights from a naive CE was arguably also an area of strength in the study, as the CE was new to pedagogical practices conducted within traditional clinical education.

Through the narrative delivered by the CE, there were clear instances of student anxiety and/or frustration with communicating with the virtual patient. These affective and cognitive reactions suggest that students were immersed in the VLE. The CE made the observation that some students disengaged from meaningful practice, which impacted on their self-reflection in the group discussion. Future VLE models may increase student support by providing supervision from within the clinical training room. This supervision component would potentially allow for formative assessment to take place through real-time support to students, resulting in increased clinical immersion with the learning process. Another recommendation would be to allow for repeated learning opportunities with several interactions with the virtual patient, to allow for incorporation and assimilation of CE feedback. Finally, students may benefit from discussions about the efficacy of VLEs in the learning process (see Merchant, Goetz, Cifuentes, Keeney-Kennicutt, \& Davis, 2014), and in particular, the similarities in learning outcomes between VLEbased and in vivo-based learning (Cook, Erwin, \& Triola, 2010) This type of information may increase student buy-in and perceptions of usefulness of the of the VLEs, both of which are critical for student learning in virtual environments (Tokel \& Isler, 2015).

Professional attitudes and experiences of university educators have traditionally influenced the choices of clinical education models used within Australian and international speech-language pathology curriculums (Sheepway et al., 2011). Further contemporary developments, and insights from the perspective of the educator, into the wider use of VLEs with virtual patients are timely. Future studies may investigate the use of an educator-controlled virtual patient for teaching related generic clinical competencies, such as interviewing skills, or providing specific counselling and education to a family or client (Syder, 1996). The virtual patient could represent clients and families of various ages and sociocultural demographics. A range of clinical case scenarios representing the scope of speech-language pathology clinical practice could also be integrated into training (Theodoros et al., 2010). Furthermore, new graduate speech-language pathologists frequently engage in interdisciplinary service delivery models when entering the workforce in adult healthcare and consequently, future investigations could explore the use of VLEs across multiple allied health programs for the clinical education of interdisciplinary practices (McAllister, 2005).

\section{Conclusion}

Through qualitative investigation of the CE's experiences, the current study provided insights regarding training using a VLE clinical education model. The CE's narrative suggests that future training of educators for undertaking clinical education in VLEs could incorporate immersive training practices. The reflections and insights offered throughout this project underscore the benefit of potentially cost-effective, large-scale, standardised alternatives to supplement traditional clinical education. An educator-controlled virtual patient in a VLE has the potential to provide greater flexibility and accessibility for students in undertaking clinical skills training prior to attending workforce placements in adult healthcare settings. Further research is needed to establish VLE clinical education models as a viable and financially sustainable option for supplementing workforce placements. The beneficial insights obtained from CEs delivering skills training in these alternative models are needed to drive improvements for future clinical initiatives. 


\section{References}

Bearman, M. (2003). Is virtual the same as real? Medical students' experiences of a virtual patient. Academic Medicine, 78(5), 538-545. Retrieved from http://journals.lww.com/academicmedicine/Fulltext/2003/05000/Is_Virtual_the_Same_as_Real_Med ical_Students_21.aspx

Braun, V., \& Clarke, V. (2006). Using thematic analysis in psychology. Qualitative Research in Psychology, 3(2), 77-101. https://doi.org/10.1191/1478088706qp063oa

Briffa, C., \& Porter, J. (2013). A systematic review of the collaborative clinical education model to inform speech-language pathology practice. International Journal of Speech-Language Pathology, 15(6), 564-574. https://doi.org/10.3109/17549507.2013.763290

Cheung, G., Chan, K., Brown, I., \& Wan, K. (2016). Teachers’ knowledge and technology acceptance: A study on the adoption of clickers. Proceedings of the International Conference on e-Learning (pp. 4651). Kidmore End: Academic Conferences International.

Cook, D. A., Erwin, P. J., \& Triola, M. M. (2010). Computerized virtual patients in health professions education: A systematic review and meta-analysis. Academic Medicine, 85(10), 1589-1602. https://doi.org/10.1097/ACM.0b013e3181edfe13

Davis, F. D. (1993). User acceptance of information technology: System characteristics, user perceptions, and behavioural impacts. International Journal of Man-Machine Studies, 38(3), 475-487. https://doi.org/10.1006/imms.1993.1022

Deladisma, A. M., Cohen, M., Stevens. A., Wagner, P., Lok, B., Bernard, T., ... Lind, D.S. (2007). Do medical students respond empathetically to a virtual patient? American Journal of Surgery, 193(6), 756-760. https://doi.org/10.1016/j.amjsurg.2007.01.021

Ferguson, A. (2005). Competency-based occupational standards: Influences on Australian speech pathology education. Folia Phoniatrica et Logopaedica, 58(1), 23-31. https://doi.org/10.1159/000088995

Foronda, C., Gattamorta, K., Snowden, K., \& Bauman, E. B. (2014). Use of virtual clinical simulation to improve communication skills of baccalaureate nursing students: A pilot study. Nurse Education Today, 34(6), e53-e57. https://doi.org/10.1016/j.nedt.2013.10.007

Health Workforce Australia (2011). Clinical supervision support program directions paper. Retrieved from http://www.hwa.gov.au/sites/default/files/clinical-supervision-support-program-directionspaper-april-2011.pdf

Health Workforce Australia (2014). Simulated learning: Expanding simulation capacity. Retrieved from https://www.hwa.gov.au/our-work/simulated-learning-environments-program/simulated-learningexpanding-simulation-capacity

Hill, A. E., Davidson, B. J., \& Theodoros, D. G. (2010). A review of standardized patients in clinical education: Implications for speech-language pathology programs. International Journal of SpeechLanguage Pathology, 12(3), 259-270. https://doi.org/10.3109/17549500903082445

Hutchings, M., \& Quinney, A. (2015). The flipped classroom, disruptive pedagogies, enabling technologies and wicked problems: Responding to 'the bomb in the basement'. The Electronic Journal of e-Learning, 13(2),106-119. Retrieved from www.ejel.org/issue/download.html?idArticle=399

Knowles, M. S., Holton, E. F., III., \& Swanson, R. A. (2011). The adult learner: The definitive classic in adult education and human resource development (7th ed.). Oxford: Butterworth-Heinemann.

Li, K. (2015). Learning styles and perceptions of student teachers of computer-supported collaborative learning strategy using Wikis. Australasian Journal of Educational Technology, 31(1), 32-50. https://doi.org/10.14742/ajet.521

Lincoln, M. (2012). The diversity challenge for universities and clinical educators. Journal of Clinical Practice in Speech-Language Pathology, 14(1), 2-6. Retrieved from https://www.speechpathologyaustralia.org.au/SPAweb/Members/Publications/Journal_of_Clinical_Pr actice.aspx

Lincoln, Y. S., \& Guba, E. G. (1985). Naturalistic inquiry. Newbury Park, CA: Sage.

Lok, B., Ferdig, R. E., Raij, A., Johnsen, K., Dickerson, R., Coutts, J., ... Lind, D. S. (2006). Applying virtual reality in medical communication education: Current findings and potential teaching and learning benefits of immersive virtual patients. Virtual Reality, 10(3), 185-195.

https://doi.org/10.1007/s10055-006-0037-3 
MacBean, N., Theodoros, D., Davidson, B., \& Hill, A. E. (2013). Simulated learning environments in speech-language pathology: An Australian response. International Journal of Speech-Language Pathology, 15(3), 345-357. https://doi.org/10.3109/17549507.2013.779024

Mamet, I., Yusoff, A. S. M., Abdullah, W. S. W., \& Razak, F. Z. A. (2015). Factors contributing preschool trainees teachers adoption of virtual learning environment: Malaysian influence. Turkish Online Journal of Educational Technology, 14(2), 73-79. Retrieved from http://www.tojet.net/articles/v14i2/14210.pdf

McAllister, L., (2005). Issues and innovations in clinical education. Advances in Speech-Language Pathology, 7(3), 138-148. https://doi.org/10.1080/14417040500181239

McAllister, L., \& Lincoln, M. (2004). Clinical education in speech language pathology London: Whurr.

Merchant, Z., Goetz, E. T., Cifuentes, L., Keeney-Kennicutt, W., \& Davis, T. J. (2014). Effectiveness of virtual reality-based instruction on students' learning outcomes in K-12 and higher education: A metaanalysis. Computers \& Education, 70, 29-40. https://doi.org/10.1016/j.compedu.2013.07.033

Mikropoulos, T. A., \& Natsis, A. (2011). Educational virtual environments: A ten-year review of empirical research (1999-2009). Computers \& Education, 56(3), 769-780. https://doi.org/10.1016/j.compedu.2010.10.020

Mimirinis, M., \& Bhattacharya, M. (2007). Design of virtual learning environments for deep learning. Journal of Interactive Learning Research, 18(1), 55-64. Retrieved from http://www.aace.org/pubs/jilr/

Moustakas, C. (1994). Phenomenological research methods. Thousand Oaks, CA: Sage.

Quail, M., Brundage, S. B., Spitalnick, J., Allen, P. J., \& Beilby, J. (2016). Student self-reported communication skills, knowledge and confidence across standardised patient, virtual and traditional clinical learning environments. BMC Medical Education, 16, Article 73. https://doi.org/10.1186/s12909-016-0577-5

Rodger, S., Webb, G., Devitt, L., Gilbert, J., Wrightson, P., \& McMeeken, J. (2008) Clinical education and practice placements in the allied health professions: An international perspective. Journal of Allied Health, 37(1), 53-62. Retrieved from http://www.asahp.org/journal-of-allied-health/

Rose, M. L. (2005). The cycle of crisis in clinical education: Why national-level strategies must be prioritized. Advances in Speech-Language Pathology, 7(3), 158-161. https://doi.org/10.1080/14417040500181353

Sheepway, L., Lincoln, M., \& Togher, L. (2011). An international study of clinical education practices in speech-language pathology. International Journal of Speech-Language Pathology, 13(2), 174-185. https://doi.org/10.3109/17549507.2011.491129

Sutcliffe, A., Gault, B., \& Shin, J. -E. (2005). Presence, memory and interaction in virtual environments. International Journal of Human-Computer Studies, 62(3), 307-327. https://doi.org/10.1016/j.ijhcs.2004.11.010

Syder, D. (1996). The use of simulated clients to develop the clinical skills of speech and language therapy students. International Journal of Language \& Communication Disorders, 31(2), 181-192. https://doi.org/10.3109/13682829609042220

Teo, T. (2010). Examining the influence of subjective norm and facilitating conditions on the intention to use technology among pre-service teachers: A structural equation modeling of an extended technology acceptance model. Asia Pacific Education Review, 11(2), 253-262. https://doi.org/10.1007/s12564009-9066-4

Theodoros, D., Davidson, B., Hill, A., \& MacBean, N. (2010). Integration of simulated learning environments into speech pathology clinical education curricula: A national approach. Canberra: Health Workforce Australia. Retrieved from http://www.hwa.gov.au/sites/default/files/sles-in-speechpathology-curricula-201108.pdf

Tokel, S. T., \& Isler, V. (2015). Acceptance of virtual worlds as learning space. Innovations in Education and Teaching International, 52(3), 254-264. https://doi.org/10.1080/14703297.2013.820139

Ward, E. C., Baker, S. C., Wall, L. R., Duggan, B. L. J., Hancock, K. L., Bassett, L. V., \& Hyde, T. J. (2014). Can human mannequin-based simulation provide a feasible and clinically acceptable method for training tracheostomy management skills for speech-language pathologists? American Journal of Speech-Language Pathology, 23, 421-436. https://doi.org/10.1044/2014_AJSLP-13-0050

Yuen, A. H. K., \& Ma, W. W. K. (2008). Exploring teacher acceptance of e-learning technology. AsiaPacific Journal of Teacher Education, 36(3), 229-243. https://doi.org/10.1080/13598660802232779

Zraick, R. I., Allen, R. M., \& Johnson, S. B. (2003). The use of standardized patients to teach and test interpersonal and communication skills with students in speech-language pathology. Advances in Health Sciences Education: Theory and Practice, 8(3), 237-248.

https://doi.org/10.1023/A:1026015430376 
Corresponding author: Janet Beilby, j.beilby@curtin.edu.au

Australasian Journal of Educational Technology (c) 2018.

Please cite as: Bánszki, F., Beilby, J., Quail, M., Allen, P. J., Brundage, S. B., \& Spitalnick, J. (2018). A clinical educator's experience using a virtual patient to teach communication and interpersonal skills. Australasian Journal of Educational Technology, 34(3), 60-73. https://doi.org/10.14742/ajet.3296 